\title{
Research on the Production Process and Artistic Features of Stone Crock Complex in Baian
}

\author{
Luo Yang*, Wang Yan \\ Chongqing Three Gorges Polytechnic College, Wanzhou, Chongqing, China
}

Keywords: Three Gorges; stone crock; production process; artistic features

\begin{abstract}
The Three Gorges is located in the Daba mountain chain, with rich and hard stones. With the gift of nature, industrious craftsmen of past dynasties had chipped stone crocks rich in the flavor of the times as well as the crock used to store water and grain by their hands with knowledge, inspiration, experience and pursuit; its shape is different with myriad forms. The carving on its crock body is rough but magnificent, exquisite and lifelike, which is the extension and display of the development of primitive art in Yangtze River basin. With the stone crock complex in Baian being an example, the thesis introduces the production process of the folk stone crock in the area of the Three Gorges, probes into its artistic value from such aspects as the shape function of crock body, constitution form, theme performance, engraving content and molding feature, and thus contributes to rescuing and studying on the folk stone crock in the area of the Three Gorges.
\end{abstract}

\section{Introduction}

In order to rescue and study on the folk stone crock in the Three Gorges area(hereinafter referred to as the Three Gorges stone crock), and protect the traditional handcraft and history and humanity left behind by the ancestors in the Three Gorges area, we carried out a thorough investigation in this field firstly, and visited the hinterland of the Three Gorges including Wushan Mountain, Fengjie, Yunyang, Wanzhou and Wuxi[1], ultimately finding that the stone crock complex in Baian is already the last treasure of the Three Gorges stone crock, most of which come from the villages and towns in such places as Wushan Mountain, Fengjie, Yunyang, Wanzhou and Wuxi before being rescued from the great Migrant movement of the Three Gorges. There are a total of 95 crocks from the Tang Dynasty to the Republic of China [2]. The economy of the Three Gorges Reservoir area is becoming increasingly prosperous and the modern living utensils become universal, so the necessary condition, being vital utensils in the past, of the Three Gorges stone crock has vanished completely. Being the representative of Three Gorges stone crock, the stone crock complex in Baian has been under protection. As for how to inherit the handcraft of engraving on stone crock, it is still worthy of real reflection.

The author thinks that the research on the Three Gorges stone crock through the research on the stone crock complex should excavate its relation with natural environment and spirit and humanity deeply, make comprehensive research and achieve the double purposes of physical protection and cultural protection instead of staying on the static protection of the heritage [3]. With many factors being considered such as the critical historical period of the stone crock complex in Baian, social background, and the folk custom in Three Gorges area, the thesis makes analyses and researches of the shape, production process, crock carving theme, modeling characteristics and Implications, in order to show the artistic value of the Three Gorges stone crock.

\section{Research Methods}

The manufacture of the stone crock is rather exquisite in workmanship. It mainly uses such methods as chiseling, planing, shaving and sawing, with sharp chisel and flat chisel being its tool. It shapes the crock body with the sharp chisel, and forms graphic decoration with a flat chisel, and then engraves the raw stone into the shape of the crock and chamfer with the help of large sharp chisel, flat chisel and hammer. Engrave the straight lines inside the crock by thin sharp chisel, with the line span 
being less than $0.5 \mathrm{~cm}$. Carve the turning point of the crock with straight lines and curves by the flat chisel of $1 \mathrm{~cm}$ [4]; sample load and sample engraving. Use the chisel tip to engrave the lines directly and then use the thin sharp chisel to engrave the fine lines with the model engraved; engrave the frame. Engrave the shape of such individuals as characters, animals and unicorns on the crock according to the engraving sample, and use the sharp chisel removes the surplus and relatively large stone; detailed engraving. Use such tools as flat chisel and gouge chisel to describe its dynamics, gestures and expressions in detail and make meticulous carving according to the characters of the figure and unicorn, from the whole picture. Engrave out the story, connotation and emotion as much as possible to highlight the figure, unicorn and the typeface; Polishing. Use such tools as gravel, chisel and sandpaper to polish the rough engraving part of the finished crock through grinding, scraping, sanding, etc, to make the glyph smooth and sleek[5].

\section{Analyses of the Research Findings}

The Shape, Function and Form. Stone crocks of different functions will be placed in different positions. For containing drinking water: the use of such stone crock has a long history, with a large number. It is often placed against the wall in the kitchen. It is often made in square shape and half-moon shape, with the length of the crock being between $80 \mathrm{~cm}$ and $150 \mathrm{~cm}$, being a must in life; fire prevention: this kind of stone crock has large capacity for water storage, which is often placed outdoor and behind the house. It is often big and thick (length, width and height $\geq$ $200 \mathrm{~cm} * 100 \mathrm{~cm} * 100 \mathrm{~cm}$, thickness $\geq 10 \mathrm{~cm}$ ) with square shape and lock shape, to be used for fire prevention; lotus growing: the shapes of this stone crock is unique and diverse, including boat shape, lotus shape, cup shape, bridge shape and so on, which is often placed in the courtyard hall and the entrance hall to greet visitors [6]. Blessing and worship: this stone crock is made according to ethics in the feudal society, which has the cultural connotations to reflect the values, thoughts and feelings and aesthetic taste of the owner [7].

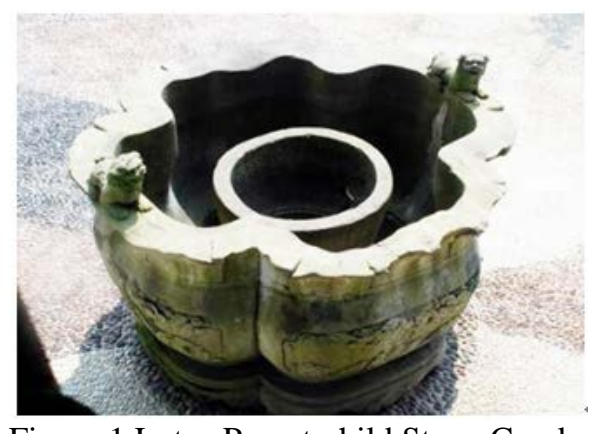

Figure 1 Lotus Parent-child Stone Crock

The constitution form of the stone crock complex in Baian can be divided into monomer composition and synthetic composition. The monolithic crock is a three-dimensional space suitable for multi -angle appreciation and research, which is completely ornamental, functional and artistic, and can co-create a unified and harmonious atmosphere with the environment around without the help of other combinations and fittings. The synthetic composition refers to the organic unity of the whole constituted by the crock itself and other collocated visual image, such as the stone crock with a base, the stone crock decorated with bridge, and the "lotus parent-child stone crock"(figure 1).

Theme. So most selections of the theme of engraving on the stone crock come from the soul worship, myths and legends and cognition in the life, with rich regional flavor, which can be summed up as five categories namely life story, farming, Imperial Examination, ethics and blessing. Life stories. The stone crock with theme of the scene of life is a typical subject in the stone crock complex in Baian Three Gorges area, which is of full composition, visual narration and vivid performance, and reflects the cultural life and funny things of the people in the slack time in Three Gorges area through objective modeling elements such as engraving of people and activities, animal image and plant 
background. The contents are as follows: contest for marriage, playing chess in court, viewing from pavilion(figure 2), desk storytelling and stage building for singing and so on[8].

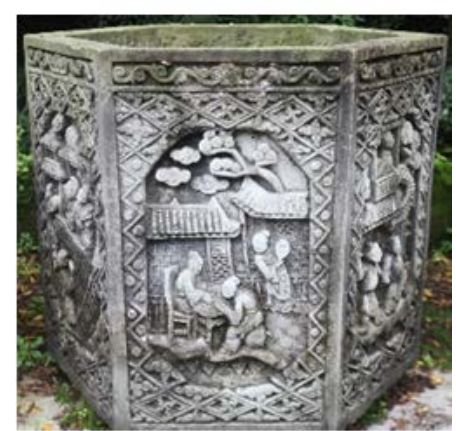

Figure 2 Hexagon Stone Crock of Life Story

Such subject of farming mainly reflects the good nature of the Three Gorges people who love to work and work diligently; the subject of the imperial examination of the stone crock originates from the ancient imperial examination system. The Chinese in past dynasties were yearning to acquire fame and the people in the Three Gorges area are no exception, hoping to get rid of poverty and live a prosperous life; feudal ethical code.

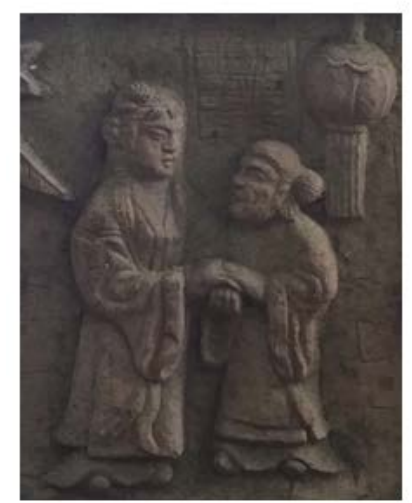

Figure 3 The Picture of Daughters and Elders

The feudal ethical code is etiquette education, which refers to the li-yue culture in Chinese traditional culture. It is also called status code, that is, teaching according to status, due to the highlight of status. The theme of feudal ethical code of the stone crock in the Three Gorges area is manifested in the identity differences between people, such as master and servant relation, and generational relations. For example, in the picture of daughter and elder(figure 3), the daughter supports the old man with her hands, with the two looking at each other warmly, and it seems to be the love in the comfortable walk and warm chat, showing the caring of younger generation to elders.

Content Analysis. Characters. The character images engraved on the Three Gorges stone crock are almost all with such three typical characteristics as short, round and fat, and the identity of different characters is obvious; rare animals and luck beast. It is common to to use the content element of rare animals and luck beast to engrave, including dragon, turtle, snake, scale, elephant, cattle, donkey and so on, with dragon, snake and fish being the most. In the decorative themes of the stone crock complex in Baian, the common plants are plum, orchid, chrysanthemum, lotus, peony, grape and so on; Each of them has its nice connotation, for example, plum represents nobleness, orchid represents integrity, chrysanthemum represents auspiciousness, lotus represents holy and grape represents more sons[9].

Decorative symbols. In the stone crock complex in Baian, the crock with rich engraving contents will use curving clouding pattern ,swastika pattern, fret, Z pattern, ancient coin pattern, convex pattern, clouding pattern and plant pattern to be trimming decoration, which is manifested with the method of "two-dimension series and four-dimension series". The use of this pattern, being a lucky 
and beautiful pattern, is to restrict the theme engraving contents into one picture range instead of expressing the mental outlook of the master of the crock directly.

Analysis and Discussion of the Modeling Features. Symbolism. In the stone crock complex in Baian, the symbolism is used most. Susan Lange once said: "The symbols used in art are a metaphor, an image that contains overt or hidden true meanings". In other words, the symbolic art is to convey its inner meaning in a metaphorical manner. The symbolic modeling is mainly manifested as such three aspects as image symbolic modeling, partial tone symbolic modeling and meaning symbolic modeling. This technique is commonly used in the engraving of the stone crock in Baian, for example, the cloud represents a male, the lotus or diamond represents a female, the peony symbolizes riches and honour, and dragon and phoenix symbolizes auspiciousness [10].

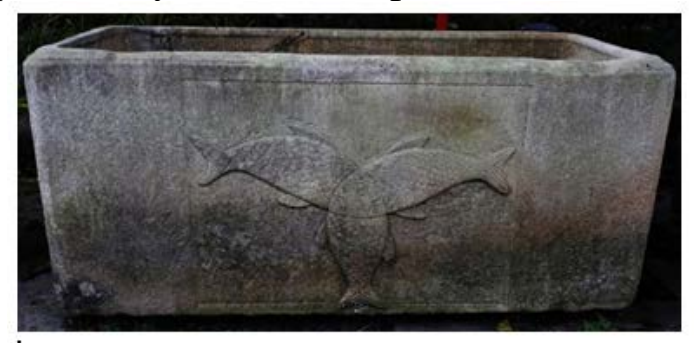

Figure 4 Tripletail Rectangle Stone Crock

Partial tone: partial tone is an expression in literature, which is also a technique often used in symbolic modeling. There appear many modellings with partial tone in the stone crock complex in Baian, such as fish, lotus, bat, magpie and beneficial beasts. Fish and surplus have the same pronunciation in Chinese, and it is easy for people to associate it with surplus things to spend; therefore, many owners of the crock will select the fish as a theme of the crock engraving, to reflect the vision, people's desire to live a prosperous life. Figure 4 is the rectangle stone crock engraved with tripletail; this composition not only has the partial tone but also contains rich thoughts of Taoism: three gives birth to everything, as fish gets the water, which can deduces the concept of natural existence as well as the integration of the heaven, the ground and human beings. With this analogy, "lotus" Symbolizes holiness and pureness and has the same pronunciation with "continuity" meaning good luck one by one.

Connotation: the metaphorical symbol modeling of the stone crock complex in Baian is mainly manifested in the combination of the image and meaning, making people gain the unique aesthetic feeling. For example, the Chinese character of Shou, as well as peach, pine and crane are the symbol of longevity; couple of fishes, couple of apes and mandarin duck are the symbol of "in pairs", meaning conjugal love; such things as lotus, pomegranate and grape symbolize being full of grandchildren, due to "more seeds".

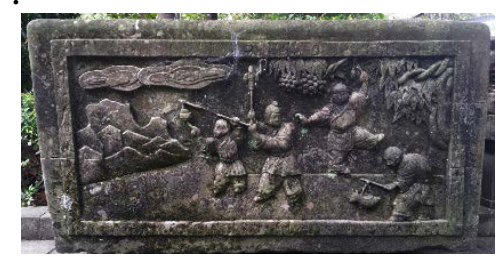

Figure 5 Rectangle Stone Crock with Character Story

Perfect: the stone crock in Baian pursues not only integrity but also beauty in modeling, to achieve the combination of integrity and beauty. In the screen layout, it pursues full and rich composition. In characters, it requires clear face and intact limbs, instead of carving half a body and half a head. The characters are all with front or side shapes. The side figure can be carved with front facial features. In the shape of the flower, half a flower is not allowed, and the flower should be big and round. As is shown in figure 5 , it is a rectangle stone crock of figure, with playing children painting on the surface of the crock, with some driving snails and some imitating storytellers to tell stories. It is full of childlike innocence and vividness, which is of high artistic value. 
Exaggerated verdancy: there are differences and relations between exaggeration and distortion. Without losing the characteristics of things, the exaggeration gets rid of the constraints of sculpting, and amplifies the unique characteristics of things. The artistic form with exaggerated deformation either resembles a thing partially in its original form, or is alike in spirit with the shape, making the specific image carved with unique from and style. Decorative characteristic: the shape and style features of the stone crock complex in Baian are formed from the folk culture in the Three Gorges area, which reflects the art with local social, cultural and folk characteristics. The decorative style reflects the rough gorgeous, delicate and vivid artistic characteristics, whose decoration techniques are often symmetry, balance,contrast, reconciliation,rhythm and continuity. The decorative pattern is often with repeated monomer, and the overall picture pays attention to the planarity, continuity, integrity and other decorative features, which reflect the folk custom and popularization of the engraving art of Three Gorges stone crock.

\section{Conclusion}

The Three Gorges stone crock is few in number now, and such precious craft as treasure has been faced with extinction. With many factors being considered such as the critical historical period of the stone crock complex in Baian, social background, and the folk custom in Three Gorges area, the thesis makes analyses and researches of the shape, production process, crock carving theme, modeling characteristics and Implications, in order to show the artistic value of the Three Gorges stone crock. The shape of the stone crock complex varies from one to another, including square shape, boat shape, half-moon shape, tripod shape, lotus shape, cup shape, lock shape, bridge shape, dou shape, altar shape, sector shape, coffin shape and so on. Located in the area of high mountains and canyons in the middle reaches of the Yangtze River, the Three Gorges area is with steep terrain, inconvenient transportation, poor cultural exchange and less external affection. So most selections of the themes of engraving on the stone crock come from the soul worship, myths and legends and cognition in the life, with rich regional flavor, which can be summed up as five categories namely life story, farming, imperial examination, ethics and blessing; the carving patterns on the stone crock in Baian are different, with graceful charming frame, exaggerated individual form, orderly-organized decorative pattern and echoing graphic character; the shape of the crock is in harmony with the decorative pattern, showing unique modeling characteristics.

\section{Acknowledgement}

The humanities and social sciences research project of Chongqing education committee, China 2014; The project name: The artistic features of the Three Gorges folk Stone cylinder. Project No. : 14SKS51

\section{References}

[1]Wei Y, Wang K, Wang W, et al. Comparison study on the emission characteristics of diesel- and dimethyl ether-originated particulate matters[J]. Applied Energy, 2014, 130(5):357-369.

[2]Xu C C, Chai Z Y, Gao Y C. Ecology, production and living: Research on the planning and construction of rural features based on the EPL system[J]. Lowland Technology International, 2013, 15(1):55-63.

[3]Sun Y M, Ding R, Li Q Q. Research on Integrated Optimization for Production Process and Steam Power System[J]. Applied Mechanics \& Materials, 2012, 229-231:995-998.

[4]Wang J F, Feng L J, Zhao Z, et al. Research on Underground Coal Mine Production Process Analysis and Informatization[J]. Advanced Materials Research, 2010, 171-172:278-282. 
[5]Watson V W M, Marciano J E. Examining a social-participatory youth co-researcher methodology: a cross-case analysis extending possibilities of literacy and research[J]. Literacy, 2015, 49(1):37-44.

[6]Koch D. On the connection between sociological, artistic, and participatory practice in research[J]. Journal Für Psychologie, 2011, 19(2):2.

[7]Rinaudo M. The production of scene : an alloy of technical, artistic and human challenges[J]. Avant Scene Opera, 2015(289):134-136.

[8]Franco F. Documenting Art as Art: The Case of Notes (2000-ongoing) by British Artist Ernest Edmonds[J]. Visual Resources, 2013, 29(4):333-352.

[9]Mayer R. Beyond the Blue Marble: Artistic research on space and ecology[J]. Acta Astronautica, 2016, 128:573-579.

[10]Li Z Y, Hu W P, Liu Y, et al. On the Influence to Social Life of the Artistic Features in the Reuse of Materials[J]. Advanced Materials Research, 2013, 818:104-107. 